\title{
Compartimentação geomorfológica da Sub-Bacia Hidrográfica do Riacho Bilheira, Taperuaba-CE, como subsídio ao planejamento ambiental*
}

\section{Renato Oliveira Barros ${ }^{1}$, Ernane Cortez Lima ${ }^{2}$}

${ }^{1}$ Graduando em Geografia. Bolsista de IC-CNPq. Universidade Estadual Vale do Acaraú. Av. John Sanford, 1845. Sobral-CE (CEP 62030-975).

2Professor Dr. do Curso de Geografia. Universidade Estadual Vale do Acaraú. Av. John Sanford, 1845. Sobral-CE (CEP 62030-975). E-mail: ernanecortez@hotmail.com.

Resumo. O presente trabalho objetiva realizar uma compartimentação geomorfológica a partir de uma análise geoambiental da Sub-Bacia Hidrográfica do Riacho Bilheira. A área em estudo está localizada a noroeste do Estado do Ceará, trata-se de uma área de aproximadamente $75 \mathrm{~km}^{2}$, inserida na Bacia Hidrográfica do Rio Aracatiaçu, que por sua vez concerne a região hidrográfica do litoral, totalmente dentro dos limites do Município de Sobral, mais especificamente dentro dos Distritos de Taperuaba e Aracatiaçu. A escolha da área deve-se a sua importância em meio ao contexto Semiárido no qual se insere e pela singularidade de seus elementos na caracterização da dinâmica natural local. Nessa perspectiva, parte-se de uma proposta metodológica geossistêmica, utilizando as categorias inferiores de análise da paisagem e compartimentação geomorfológica. Utiliza-se como ferramentas básicas, sistemas de informações geográficas SIG, análise de imagens de satélite Landsat 8 e dados temáticos da área. A partir do cruzamento dessas informações constatou-se que a área em estudo possui três unidades geomorfológicas, Inselbergues, Planície Fluvial e Depressão Sertaneja. Há uma descaracterização acentuada da mata ciliar, solos desnudos, assoreamento das nascentes de riachos e desmatamentos indiscriminados da cobertura vegetal natural. Dessa forma, o estudo integrado surge como uma ferramenta importante que auxilia as ações de planejamento ambiental direcionadas para a conservação dos recursos naturais.

Palavras-chave: Análise geoambiental; Geossistema e Relevo.

Abstract. Geomorphological compartmentation of the Sub-Basin of the Bilheira River, Taperuaba-CE, as support to environmental planning. The present work aims at to accomplish a geomorfologic compartimentation starting from an analysis geoenviroment of the hidrografic Sub-Basin of the Bilheira River. The area in study is located to Northwest of the Ceará's State, it is treated of an area of approximately $75 \mathrm{~km}^{2}$, totally inserted in the Basin Hidrografic of the Aracatiaçu River that concerns the area hidrografic of the coast for the time limits of the Municipal District of Sobral, more specifically
Recebido:

29/07/2016

Aceito:

02/09/2016

Publicado:

30/09/2016

Acesso Aberto Artigo completo

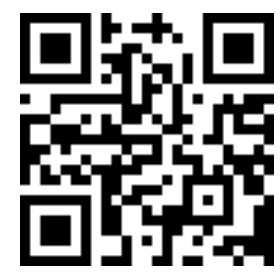

ORCID

(1) 0000-0002-4232-9790 Renato Oliveira Barros (1) 0000-0002-1744-6928 Ernane Cortez Lima

\footnotetext{
*Apresentado no V Congresso Brasileiro de Educação Ambiental Aplicada e Gestão Territorial, Fortaleza/CE, 8 a 11/06/2016.
} 
inside of the District of Taperuaba and Aracatiaçu. The choice of the area is due to the importance of this environment in Semiarid's context and for the singularity of their elements in the characterization of the dynamics natural place. In that perspective, was propose a methodological geossistemic, using the inferior categories of analysis of the landscape and for the geomorfologic compartimentation. It is used as basic tools, SIG, analysis of satellite images Landsat 8 and thematic data of the area, starting from the crossing of those information were verified that the area in study possesses three geomorphologic units, Inselbergs, Fluvial Plain and Depressão Sertaneja. There are an accentuated descaracterization of the ciliary forest, nude soils, silting of the East of streams and indiscriminate deforestations of the natural vegetable covering. In that way, the integrated study appears as an important tool that it aids the actions of environmental planning addressed for the conservation of the natural resources.

Keywords: Analysis geoambiental; Geossistema and Relief.

\section{Introdução}

Indubitavelmente, a forma como a sociedade apropria-se da natureza interfere diretamente/indiretamente na estrutura socioeconômica de uma determinada área, e essa nova estrutura socioeconômica formada tenderá a modificar ainda mais as condições ambientais existentes, se fazendo necessário amiúde de uma compreensão dessas transformações.

Nessa perspectiva, buscar entender o fenômeno ocasionado é antes de tudo, propor uma ação preventiva daquilo que poderá uma vez ou outra provocar um dano de maior escala tanto na estrutura social como na ambiental.

Lima (2012) entende que a região nordeste do Brasil é castigada pelas secas que trazem inúmeras desvantagens do ponto de vista econômico e social para os estados que a compõem. Sendo que o estado do Ceará não foge a regra, apresentando, dentre outros problemas, 0 entrave econômico atrelado ao fenômeno das secas. Onde se faz necessário procurar alternativas para amenizar tal fato.

Trentin et al. (2012) analisa que os estudos geomorfológicos podem contribuir no planejamento e na conservação dos recursos naturais, estabelecendo formas racionais de uso destes recursos, sem alterar bruscamente o equilíbrio do ecossistema. Ainda de acordo com o autor estes estudos permitiram ainda a análise espaço-temporal dos processos atuantes no modelado do relevo terrestre, possibilitando a identificação ou a prevenção de processos de degradação ambiental que se achem relacionados aos elementos físicos.

Dessa forma, no presente trabalho tem-se como objetivo geral fazer uma compartimentação geomorfológica da SubBacia Hidrográfica do Riacho Bilheira como subsídio ao planejamento ambiental, para se chegar a esse objetivo a caracterização dos componentes geoambientais da área de estudo foi de extrema importância.

Para a seguinte pesquisa utilizou-se o método geossistêmico voltado para os estudos geográficos, pois o mesmo nos dá a oportunidade de conceber o objeto de estudo de uma maneira interligada, e se tratando de bacias hidrográficas onde possui diversos atributos concebíveis 0 geossistema é visto como imprescindível.

\section{Localização da área de estudo}

A sub-bacia em estudo possui uma área de aproximadamente 75 km², localizase a noroeste do Estado do Ceará, pertencendo à Bacia Hidrográfica do Rio Aracatiaçu, que por sua vez concerne à região hidrográfica do litoral, inserida totalmente dentro dos limites municipais de Sobral, mais especificamente dentro dos 
limites dos Distritos de Taperuaba e Aracatiaçu. Limita-se ao sul e sudoeste com o Município de Santa Quitéria (Distrito de
Logradouro), a sudeste, nordeste e norte com o Distrito de Taperuaba, e ao noroeste com o Distrito de Aracatiaçu (Figura 1).
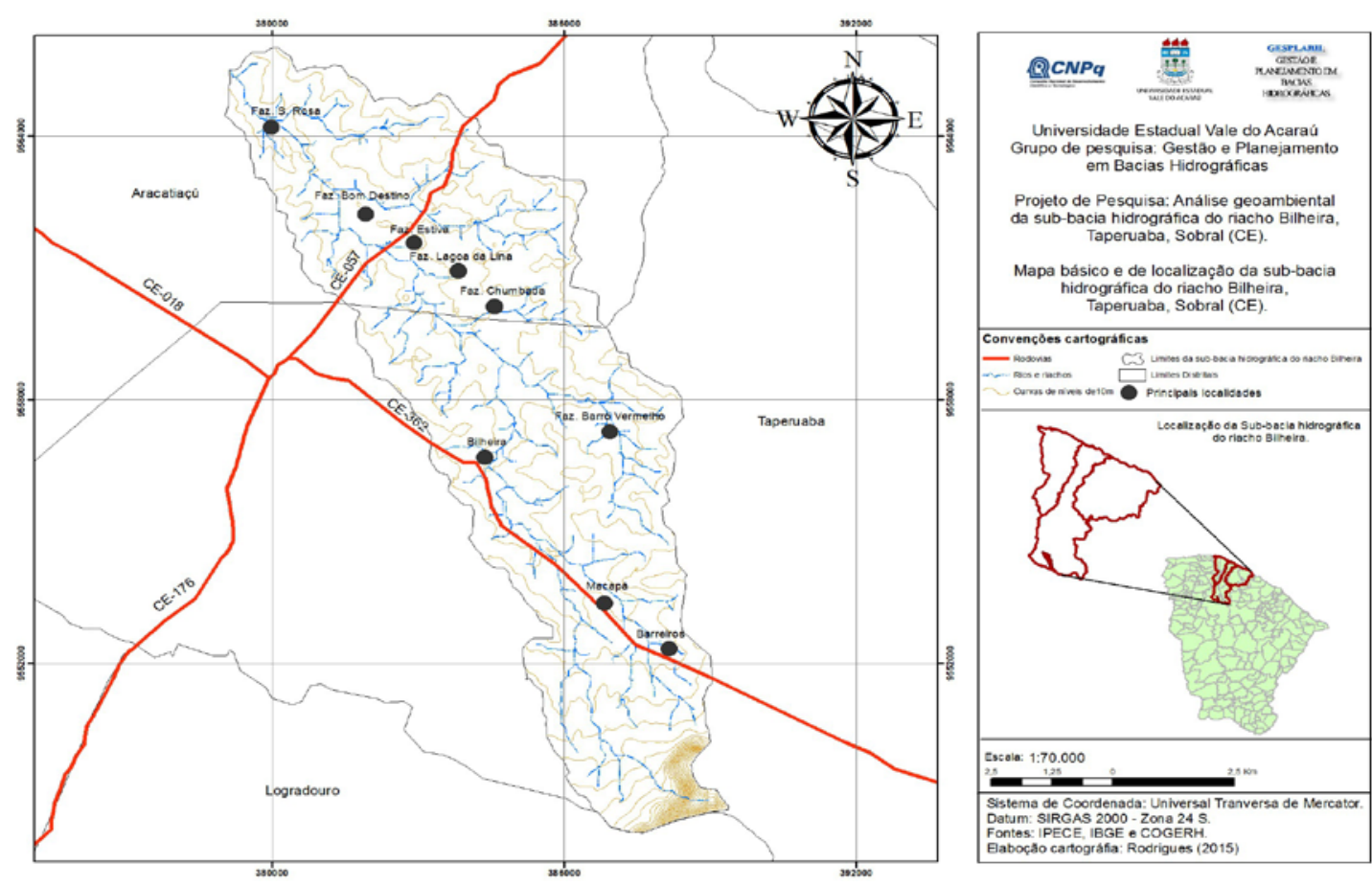

Figura 1. Localização da área de estudo. Fonte: Rodrigues (2016).

\section{Fundamentos teóricos-metodológicos}

Esta pesquisa está ancorada na análise geossistêmica, onde estes estudos buscam analisar de maneira holística e integrada as variáveis ou elementos que compõem um sistema e suas interconexões, suas perdas e ganhos de energia e matéria.

Lima (2012) analisa que nos últimos anos tem havido uma grande preocupação com o meio ambiente, tendo como consequência uma ampliação e ao mesmo tempo um significativo desenvolvimento das ciências que tratam das questões ambientais. Isso tem ocorrido em vista à intensa degradação ambiental dos recursos naturais que têm alcançado proporções em nível mundial.

Portanto a presente pesquisa fundamenta-se na concepção geossistêmica que é teoricamente justificada na Teoria Geral dos Sistemas (TGS), a qual é baseada nas relações mútuas entre seus componentes, buscando analisar os fenômenos fundamentalmente através da organização e das inter-relações entre os elementos que o compõem.

Bertrand (1972) coloca o geossistema como um complexo dinâmico espaço-temporal usado na identificação e delimitação das unidades geossistêmicas. Considerando a paisagem como o resultado dinâmico da combinação instável "[...] dos fatores físicos, biológicos e antrópicos que, reagindo dialeticamente uns sobre os outros, fazem da paisagem um conjunto único e indissociável, em constante evolução".

Para Troppmair (1985), o geossistema é um espaço amplo com certa homogeneidade em seus componentes, estruturas, fluxos, e relações que se integram e forma o meio físico passível da ação biológica, que possuem três características fundamentais a morfologia a dinâmica e a exploração biológica, sendo a 
morfologia a expressão física do arranjo dos elementos e da consequente estrutura espacial; a dinâmica - O fluxo de energia e matéria que passa pelo sistema no que varia no espaço e no tempo; e a exploração biológica - Flora, fauna e solo.

Tricart (1977) concebe a análise geossistêmica através da classificação ecodinâmica e sua aplicação no estudo da paisagem propõe três tipos de meios morfodinâmicos: meios estáveis, meios intergrades ou de transição e meios fortemente instáveis.

Funceme (2009) onde nesse trabalho sintetizou a contextualização geoambiental do estado do Ceará pondera que os sistemas ambientais (geossistemas) são integrados por variados elementos que mantém relações mútuas entre si e são continuamente submetidos aos fluxos de matéria e de energia.

Nessa perspectiva para Penteado (1983) energia é a força que conduz o sistema ao funcionamento gerando capacidade de realizar trabalho. Enquanto, matéria é todo material que circula através do sistema. Dessa forma, ambos circulam no geossistema através de canais, constituindo os fluxos.

Troppmair e Galina (2006) concluem que o Geossistema é um sistema natural, complexo e integrado onde há circulação de energia e matéria e onde ocorre exploração biológica, inclusive aquela praticada pelo homem. Pela ação antrópica poderão ocorrer pequenas alterações no sistema, afetando algumas de suas características, porém estes serão perceptíveis apenas em micro-escala e nunca com tal intensidade que 0 Geossistema seja totalmente transformado, descaracterizado.

Nesse contexto, percebe-se que nos últimos anos o estudo dos geossistemas tem ganhado importância e aplicação crescente e, entre outros objetivos, procura a conservação o uso racional e o desenvolvimento do espaço geográfico beneficiando toda biosfera, em especial, a sociedade humana.

Para a realização dessa pesquisa se fez necessário o estudo inicialmente de gabinete, onde se buscou na literatura autores que trabalham com o método geossistêmico onde nos deparamos com os pesquisadores Bertrand (1972), Penteado (1983), Tricart (1977), Troppmair (1985; 2006). Partindo do pressuposto do trabalho ser executado em uma unidade espacial no caso a Sub-bacia hidrográfica partimos na iniciativa de compreender os processos atuantes na bacia hidrográfica como também a parte de planejamento e gestão da mesma, para isso a colaboração de autores, como: Costa (2015), Lima (2012), Rodrigues (2016), foram essenciais. E por fim, para chegarmos ao objetivo teóricometodológico desse trabalho, ou seja, a compartimentação geomorfológica e também a análise geoambiental fez-se um apanhado a partir da ajuda metodológica de: Souza et al. (1979) e Trentin et al. (2012).

A primeira etapa consistiu exatamente no levantamento de materiais bibliográficos e geocartográfico, que foram essenciais para o auxílio da segunda etapa que baseou-se na realização do trabalho de campo, para isso se fez necessário o mapa básico da área de estudo, as cartas topográficas matricial da SUDENE compreendidas nas Folhas SB.24-V-B-I (Santa Quitéria) e SA.24-X-D-IV (Sobral), na escala de 1:100.000 disponibilizadas DSG/SUDENE. O uso de GPS (Sistema de Posicionamento Global), martelo, fita métrica, trena, prancheta e máquina fotográfica foram elementos utilizados para auxiliar e fornecer as informações necessárias.

Através dos trabalhos de campo obtêm-se, de forma empírica, os fatos espaciais dos elementos geoambientais e da dinâmica estabelecida entre esses elementos, caracterizando a fisionomia da paisagem, assim como também em coleta de dados referentes aos aspectos socioambientais e do uso e ocupação, fornecendo informações básicas sobre 0 grau de degradação nos diferentes setores da área.

Além do mais, a produção cartográfica básica foi confeccionada no SIGs Quantum Gis, versão 2.4, a escolha deu-se exatamente por ser um software gratuito e de fácil manipulação, para isso a 
interpretação de imagens de satélite Landsat 8, disponíveis no catálogo de imagens do Instituto Nacional de Pesquisas Espaciais (INPE) e no U.S Geological Survey (USGS), foram basilares para realizar essa etapa e contribuir satisfatoriamente com $\mathrm{o}$ andamento programático da pesquisa.

Para realizar a compartimentação geomorfológica da Sub-Bacia Hidrográfica do Riacho Bilheira, utilizou-se a metodologia de Souza et al. (1979), que fez uma compartimentação do Estado do Ceará, usando dados topográficos, resultando sua pesquisa em nove unidades observadas, porém para a área de estudo da pesquisa em questão foram encontradas apenas três unidades, Depressão Sertaneja, Inselbergues e planícies fluviais. Em relação aos dados utilizados para as condições climáticas usamos trabalhos acadêmicos já desenvolvidos que retratam de forma clara e verídica do clima em análise.

Para a identificação dos tipos de solos predominantes na área, teve-se como base a segunda edição do Sistema Brasileiro de Classificação de Solos (SIBCS), elaborado pela EMBRAPA (2006). A distribuição fitogeográfica foi baseada na proposta de Fernandes (1990). A escolha por essa metodologia foi por entender que a mesma possibilita melhor adequação à escala de trabalho proposta inicialmente. Os aspectos socioeconômicos e o uso e ocupação foram empiricamente compreendidos através dos trabalhos de campo e através de conversas informais com moradores das comunidades, que convivem e mantêm estreita relação com os recursos naturais da área da sub-bacia.

A drenagem da área da sub-bacia bem como de todo seu contexto apresentase dendrítico e subdendrítico. Para realização da análise, a Sub-bacia foi subdividida em setores denominados de Alto, médio e baixo cursos, essa divisão considerou critérios de altitude do relevo, assim o alto curso da sub-bacia localiza-se entre as altitudes de 300 a $650 \mathrm{~m}$, o médio está sobre as altitudes de 170 a $300 \mathrm{~m}$ e o baixo 90 a $170 \mathrm{~m}$.

\section{Resultados e Discussões}

\section{Caracterização dos componentes geoambientais da Sub-Bacia Hidrográfica do Riacho Bilheira}

De acordo com Rodrigues (2016) a caracterização dos componentes geoambientais torna-se de fundamental importância quando se tem a análise ambiental como diretriz para o seu desenvolvimento, pois a análise interdependente de tais elementos possibilita uma compreensão mais complexa e vindoura para o planejamento ambiental.

Os aspectos geológicos refletem sobre os tipos de solos, e também sobre a disponibilidade de recursos hídricos superficiais e sub-superficiais, influenciando também o quadro fitoecológico local, assim como também as potencialidades dos recursos naturais disponíveis (Rodrigues, 2016).

Constatou-se que a área da subbacia é formada por grandes variedades de formações litológicas. Em maior detalhe identificou-se as seguintes unidades geológicas: Depósitos Sedimentares Cenozóicos e Complexo Tamboril Santa Quitéria, os tipos de rochas identificadas constituem-se de rochas ígneas plutônicas formadas por intrusão, com exceção dos Depósitos Sedimentares.

Os Depósitos Sedimentares Cenozóicos são compostos por argilas, areias, quartzosas e quartzofeldspáticas, conglomeráticas ou não, cascalhos e argilas orgânicas/fluvial, de granulação grosseira. Esta unidade aparece de forma mais intensa no baixo curso onde o gradiente dos canais é baixo, possibilitando o processo de acumulação.

A Suíte Intrusiva Tamboril-Santa Quitéria, esta área apresenta-se composta por associação granito-migmatítica, envolvendo granitoides neoproterozóicos, cinzentos e rosados, de granulação variável até termos porfiríticos, gnaissificados ou não, em jazimentos de geometrias e dimensões diversas; ortognaisses migmatíticos, além de rochas calcissilicáticas e anfibolitos. Essa unidade 
é mais expressiva na área da sub-bacia estando presente em todos os seus setores.

Tratando-se do relevo,
consideramos a reflexão de (Lourenço, 2013), os aspectos geomorfológicos estão ligados aos "indicadores morfoestruturais, litológicos e climáticos, controlados por fatores dinâmicos como o clima, a tectônica e pedogênese, associados aos fatores estáticos [...]”. Devido a essa complexa relação, resultam as várias sequências morfológicas, vislumbrando as diversas formas de relevo.

$\mathrm{Na}$ área de estudo, as unidades geomorfológicas existentes são a Depressão Sertaneja, representando toda parte de relevo mais rebaixado, e por ventura a unidade prevalecente em toda a área da Sub-Bacia Hidrográfica do Riacho Bilheira, Inselbergues correspondem as áreas de nascente, são locais de declividade bastante acentuadas com vales em forma de "V", onde se pode constatar uma predominância das rochas graníticas. A planície fluvial que ocupa toda a extensão do leito do Riacho Bilheira, resultantes do acúmulo de sedimentos.

A Figura 2, complementa esta caracterização com uma visão representativa destas unidades geomorfológicas da sub-bacia.

\begin{tabular}{|c|c|c|c|}
\hline & $\begin{array}{c}\text { Unidades } \\
\text { Geomorfológicas }\end{array}$ & $\begin{array}{c}\text { Feiçóes } \\
\text { Morfológicas }\end{array}$ & Características Específicas \\
\hline Depressão Sertaneja & $\begin{array}{c}\text { Superfície de } \\
\text { aplainamento-sertões } \\
\text { do Riacho Bilheira. }\end{array}$ & $\begin{array}{c}\text { Formas deprimidas com } \\
\text { superfícs erodidas planas e/ou } \\
\text { ligeiramente dissecadas }\end{array}$ \\
\hline Inselbergues & $\begin{array}{c}\text { Serras secas do } \\
\text { complexo granítico } \\
\text { do corrente }\end{array}$ & Formas residuais dissecadas \\
\hline \multirow{2}{*}{ Planície Fluvial } & $\begin{array}{c}\text { Planície fluvial do } \\
\text { riacho Bilheira }\end{array}$ & Formas de acumulação \\
\hline
\end{tabular}

Figura 2. Síntese das unidades morfoesculturais da sub-bacia do riacho Bilheira. Fonte: Adaptado de Costa (2015).

No que se refere às condições climáticas a área de estudo se insere dentro do estudo da Funceme (2009), onde ele afirma que quase toda a totalidade do Ceará é submetida às influências de clima semiárido quente que ainda representa o principal condicionante desfavorável ao aproveitamento e utilização dos recursos naturais.
Diniz et al. (2008) analisa o clima semiárido da região como o principal fator condicionante da dinâmica ambiental. As temperaturas elevadas, geralmente situando-se entre $25^{\circ} \mathrm{C}$ e $29^{\circ} \mathrm{C}$, resultam índices de evapotranspiração superiores a $1.000 \mathrm{~mm}$ anuais. As chuvas ocorrem de forma bastante irregular ao longo do ano, com caráter torrencial no primeiro semestre. 
De acordo com os estudos de Rodrigues (2016), o Distrito de Bilheira apresentou, em 2000, a média anual de $61,2 \mathrm{~mm}$, e, em 2009, foi de 107,6 mm, sendo estes os anos mais chuvosos. Os anos com as menores médias pluviométricas foram o ano de 2005, com 24,8 mm, e 2007, com 39,4 mm, apresentando uma média anual total de $50,3 \mathrm{~mm}$ para os 17 anos analisados. Pode-se perceber e corroborar com as informações anteriores, que as precipitações pluviométricas no semiárido acontecem ocasionalmente no primeiro semestre do ano de maneira irregular e espacializada.

As classes de solos que correspondem à área da sub-bacia hidrográfica do Riacho Bilheira foram identificadas tanto em trabalhos de gabinete através da classificação do SIBCS (2006), como através do exame morfológico do perfil realizado em trabalho de campo.

Conforme o Sistema Brasileiro de Classificação de Solos (SIBCS, 2006), foram identificadas na área da Sub-Bacia Hidrográfica do Riacho Bilheira três tipos de solos, Neossolos Flúvicos, Neossolos Litólicos e Luvissolos.

Os Neossolos Flúvicos originam-se de sedimentação fluvial do holoceno; são solos pouco desenvolvidos, apresentando, sequencialmente, os horizontes A e C. São de médio a muito profundos, com textura variando de arenosa para argilosa, com drenagem moderada a imperfeita, são ricos em constituintes primários com fácil decomposição, essencial à vida das plantas. Nas áreas em estudo, são identificados adjacentes aos rios e riachos da sub-bacia.

Os Neossolos Litólicos são solos pouco evoluídos, sem $\mathrm{o}$ horizonte $\mathrm{B}$, apresentando o horizonte A seguindo pelo C ou R. Para Lourenço (2013), este tipo de solo apresenta o horizonte A diretamente sobre a rocha-horizonte $\mathrm{R}$, sendo comum encontrar superficialmente pedregosidade e/ou rochosidade, podendo ser vinculados aos afloramentos rochosos. Na área de estudo é encontrada em quase todos os setores da bacia.

Os Luvissolos apresentam 0 horizonte B textural seguido pelo horizonte A ou E, com argila de alta atividade da parte mais superficial com acumulação nos horizontes sub-superficiais. São solos bem ou imperfeitamente drenados, com pouca profundidade, podendo apresentar pedregosidade superficial. Este tipo de solo na Sub-Bacia do Riacho Bilheira é encontrado a N-NW.

O perfil dos solos acima descritos ver (Figura 3), o ordenamento dos perfis se encontra em ordem descrita na apresentação do texto de forma respectiva, da esquerda para a direita temos: Neossolos Flúvicos, Neossolos Litólicos e Luvissolos.

Para a classificação da vegetação da sub-bacia hidrográfica do riacho Bilheira, optou-se pelo sistema de classificação de Fernandes (1990). Este classifica o conjunto vegetacional do Ceará sob dois aspectos: o fisiográfico e o fitogeográfico. De acordo com esse mesmo autor a área de estudo está sob o domínio dos sertões e das serranias, para a feição dos sertões, tem-se a seguinte distribuição da vegetação na área da pesquisa.

A Caatinga alta com estrato arbóreo, arbustivo/subarbustivo e estrato herbáceo, identificadas nas maiores elevações (inselbergues) da área, destacando-se o pau-branco (Auxemma oncocalyx), jucazeiro (Caesalpinia ferrea), aroeira (Astronium fraxinifolium). A caatinga baixa se constitui em dois padrões, um mais denso e outro mais aberto, com afloramentos rochosos, apresentando apenas dois estratos: arbustivo/subarbustivo e herbáceo, com espécies como o xiquexique (Ploceurus gounelli), pereiro (Aspidosperma pirifolium), mofumbo (Cobretum leprosum), jurema preta (Mimosa tenuiflora), recobrindo quase que totalmente a área da pesquisa.

O carnaubal (mata de várzea), localizado nos vales do Riacho Bilheira e seus tributários, exercendo um importante papel econômico devido à extração da cerade-carnaúba, assim como a produção de artesanato, com as palhas da mesma, destacando-se a carnaubeira (Copernicia prunifera) e o jucazeiro (Caesalpinia ferrea).

Vegetação ribeirinha identificada às margens do Riacho Bilheira e seus tributários. Esse tipo de vegetação 
encontra-se em solos de aluvião, com maior teor hídrico. As espécies identificadas foram oiticica (Licania rigida) e a ingazeira (Lonchocarpus sericeus). No entanto, devido ao desmatamento, estas espécies sedem lugar a outras espécies características da caatinga baixa, como o mofumbo (Cobretum leprosum), na área de estudo essas espécies foram encontradas em quase todos os setores da bacia, mormente nos diques marginais.

O conhecimento das formas de uso e ocupação da terra é de fundamental importância, pois é a partir do manejo inadequado que ocorre a deterioração dos recursos naturais.

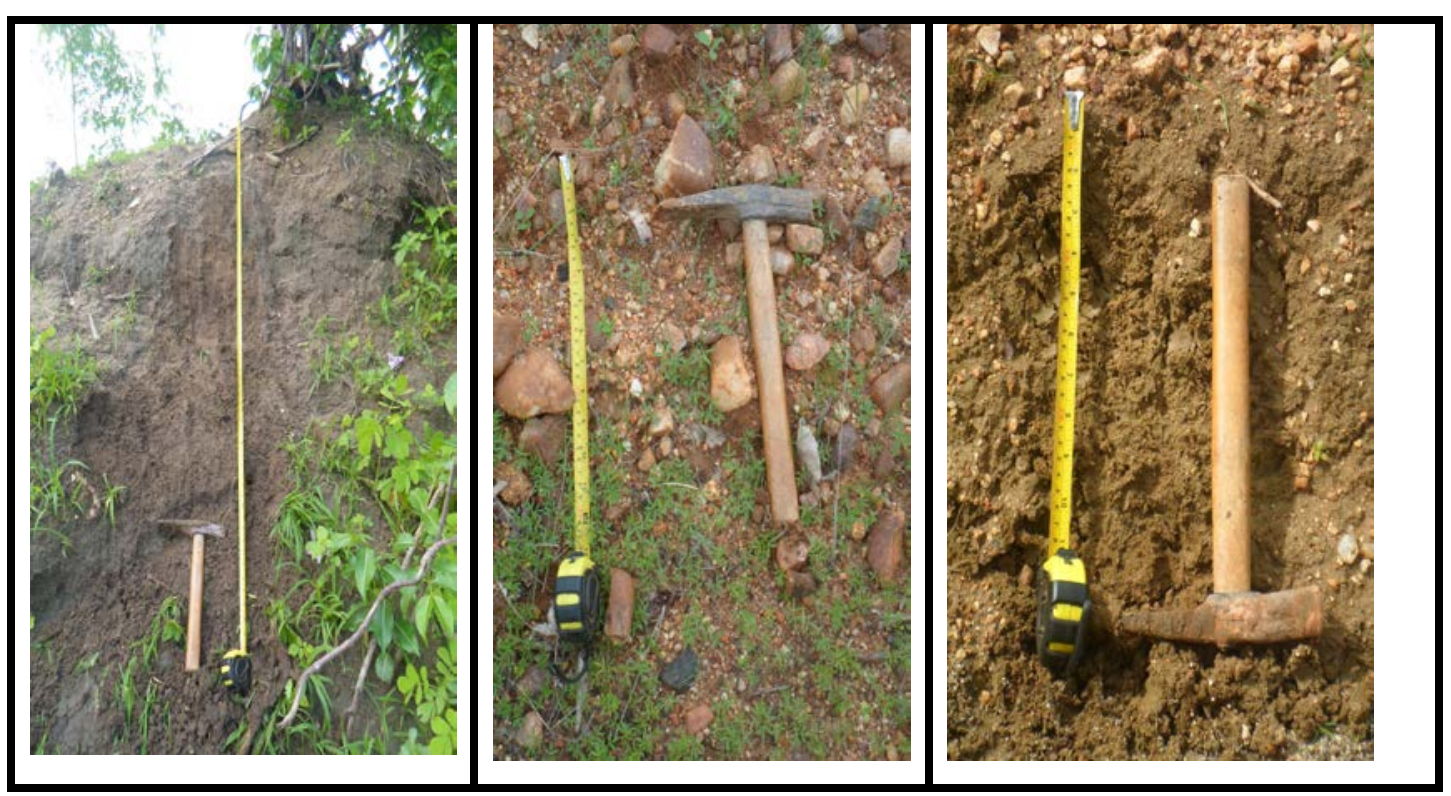

Figura 3. Perfil dos solos encontrados na Sub-Bacia Hidrográfica do Riacho Bilheira.

O uso e a ocupação da área devemse ao surgimento das comunidades identificadas na área, constituindo principalmente de fazendas que estão distribuídas ao longo da planície fluvial foram contabilizadas nove comunidades existentes sendo que sete delas ocupam a margem direita do riacho ocasionalmente percebeu-se que a mesma apresenta o maior índice de descaracterização. As principais atividades envolvem as práticas da agricultura de subsistência, a pecuária extensiva, havendo também construções de residências.

A agricultura de subsistência é encontrada em toda sub-bacia do Riacho Bilheira trata-se de uma atividade milenar que ainda hoje possui métodos como o destocamento, coivaras e a queimada da vegetação, isso acaba gerando um desequilíbrio ambiental e por ventura acelerando os processos erosivos na região como também posteriormente assoreando as nascentes dos recursos hídricos como bem já é visto na área em estudo.

A agropecuária extensiva exerce influência significante frente ao uso e ocupação, tornando-se um fator fundamental no povoamento da área, como é característico de todo o território semiárido, esta que na área se dá através da criação bovina, caprino e ovino.

A prática de barramentos em forma de pequenos açudes e barragens é amplamente constatada ao longo dos setores da sub-bacia, a formação desses pequenos reservatórios visa a uma maior acumulação de água para a prática da pesca e dessedentação de animais nos meses de estiagem.

No que se refere ao desmatamento é possível classificá-lo como uma ação que desequilibra a ocorrência de todos esses processos no meio natural. Sua ocorrência 
se dá principalmente pela prática das atividades agrícolas, para a ampliação de áreas de pastagem e para o forte extrativismo vegetal na área.

Com relação à mata ciliar a mesma encontra-se bastante descaracterizada tanto na margem direita como na margem esquerda ao longo da planície fluvial, o setor da bacia que possui o maior índice de preservação encontra-se no alto curso e isso se deve, sobretudo, pela baixa concentração populacional. O dique marginal do Riacho Bilheira, partindo do nível de base local tanto em relação à margem direita como esquerda, varia de $1 \mathrm{~m}$ de altura a $3 \mathrm{~m}$, em relação ao nível de superfície.

A Figura 4 mostra de maneira esquemática a síntese da caracterização dos componentes geoambientais encontrados na sub-bacia hidrográfica do Riacho Bilheira através do perfil Longitudinal na direção Norte-Sul.

PERFIL LONGITUDINAL DO RIACHO BILHEIRA, TAPERUABA, SOBRAL (CE)

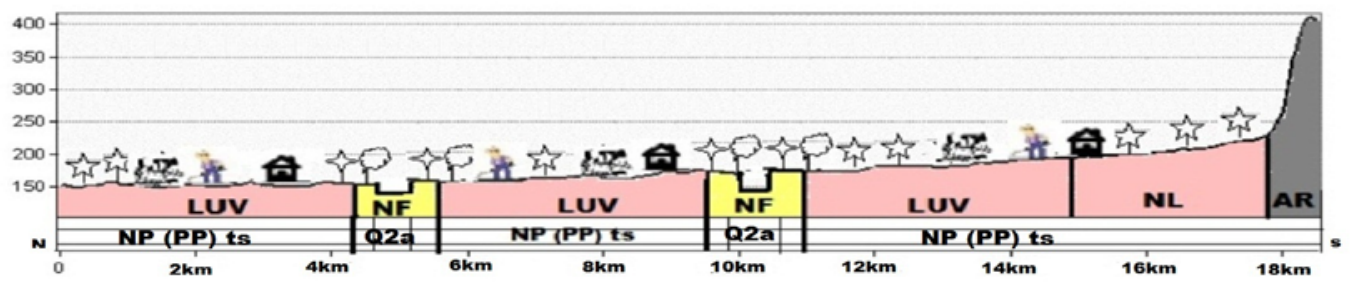

LEGENDA
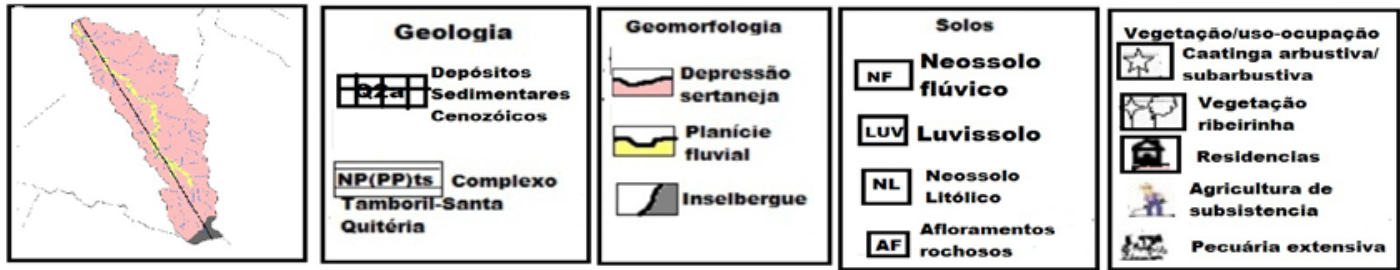

Figura 4. Perfil Longitudinal do riacho Bilheira na direção Norte-Sul.

\section{Compartimentação geomorfoló- gica da Sub-Bacia Hidrográfica do Riacho Bilheira}

O estudo das formas de relevo norteia-se como o objeto de estudo da geomorfologia, tanto referente aos aspectos de gênese como evolução destas formas. Todavia, o relevo por mais que pareça estático, ele está em constante processo de evolução, com "velocidades" variadas, e interagindo a todo momento com os demais componentes da paisagem (Trentin et al., 2012).

Em conformidade com o autor supracitado, considera que as formas de relevo não são componentes independentes na paisagem e, consequentemente, a sua evolução também não é. Quando se pretende entender a evolução da forma de relevo de uma determinada área, torna-se necessário considerar as características geológicas, climáticas, hidrológicas, pedológicas e biológicas da respectiva área, bem como a ação antrópica, pois o homem também é um componente do meio e um agente modificador de extrema atuação.

Portanto, entende-se que a paisagem não é a simples adição de elementos geográficos espacializados. É, em uma determinada porção do espaço, o resultado da combinação dinâmica, portanto instável, de elementos físicos, biológicos e antrópicos que, reagindo dialeticamente uns sobre os outros, fazem da paisagem um 
conjunto único e indissociável, em perpetua evolução (Bertrand, 1972).

Nessa perspectiva, para realizar a compartimentação geomorfológica utilizamos a metodologia de Souza et al. (1979), onde o mesmo realiza a compartimentação topográfica do Estado do Ceará em nove unidades, embasadas na variação topográfica, morfoestrutural e escultural, sendo que na área em estudo encontramos apenas três das unidades por ele descrita, são elas Inselbergue, Planície Fluvial e Depressão Sertaneja. Para constar, ressaltase que foi imprescindível a análise ambiental proposta, visto que atuou como uma ferramenta essencial para se chegar nessa etapa.

Souza et al. (1979) interpreta Inselbergue como sendo formas disseminadas pela depressão sertaneja que efetivam os efeitos seletivos de trabalho erosivo no decorrer da história geológica recente da região. São geralmente áreas despidas de solo ou vegetação e quando a pedogênese se efetiva, conduz à formação de solos litólicos, recobertos por uma caatinga de porte arbustivo. O significado agrícola destas formas não tem muita expressão.

$\mathrm{Na}$ área da pesquisa essa unidade geomorfológica encontra-se no extremo sul, trata-se do complexo granítico do Corrente configurando como o alto curso da subbacia, apresentando altitudes superiores a $600 \mathrm{~m}$ de altitude além do mais é nessa área onde encontramos o maior índice de preservação das nascentes do riacho Bilheira e assim como dos seus tributários também.

A Planície Fluvial de acordo com o autor supracitado representam típicas formas de deposição fluvial que por oferecerem melhores condições de utilização agrícola, contrastam com os setores interfluviais com solos mais limitativos para aquele tipo de uso. Dentre estas planícies as mais expressivas foram formadas pelos Rios Jaguaribe, Banabuiu, Salgado, Acaraú, Aracatiaçu, dentre outros. Transversalmente, podem ser observadas nestas planícies, setores bem homogêneos e claramente identificados: A vazante compreende basicamente o talvegue e o leito menor do rio, podendo ser submetido a cheias periódicas.

Cumpre salientar finalmente que apesar das planícies fluviais constituírem pequenos compartimentos de relevos de disposição longitudinal as possibilidades que oferecem às atividades agrícolas, conferem às mesmas, importância das mais significativas. Na área de estudo a mesma está representada pelo riacho Bilheira e seus tributários favorecendo a distribuição populacional ao longo do seu curso.

No que se refere à Depressão Sertaneja, compreende em termos de extensão geográfica, a unidade de maior expressividade, representa uma superfície embutida, entre planaltos cristalinos e/ou sedimentares, com níveis altimétricos variáveis entre 100 e $350 \mathrm{~m}$, com topografia expressivamente aplainada ou ligeiramente ondulada e recoberta por caatingas de porte e flora bastante diferenciáveis, conforme a localização. Na região em estudo os dados colocados acima conferem os mesmos resultados.

Na Figura 5, para termos interpretativos, propusemos a confecção de um mapa para evidenciar e mostrar com exatidão onde se encontra essas formas de relevo elencadas.

\section{Conclusões}

A partir da metodologia utilizada neste trabalho pautada na análise geossistêmica e dos resultados alcançados foi possível interpretar de uma maneira integrada os elementos encontrados na área de estudo, percebeu-se que a mesma possui uma rica diversidade em seu meio físiconatural e apresenta diferenciações em seus aspectos sociais e naturais.

A análise ambiental da Sub-Bacia Hidrográfica do Riacho Bilheira demonstra que suas unidades geoambientais apresentam formas de uso e ocupação onde prevalece com expressividade a agricultura de subsistência, o extrativismo vegetal e a pecuária extensiva de gado bovinos, caprinos e ovinos, onde os impactos ambientais registrados na área se devem 

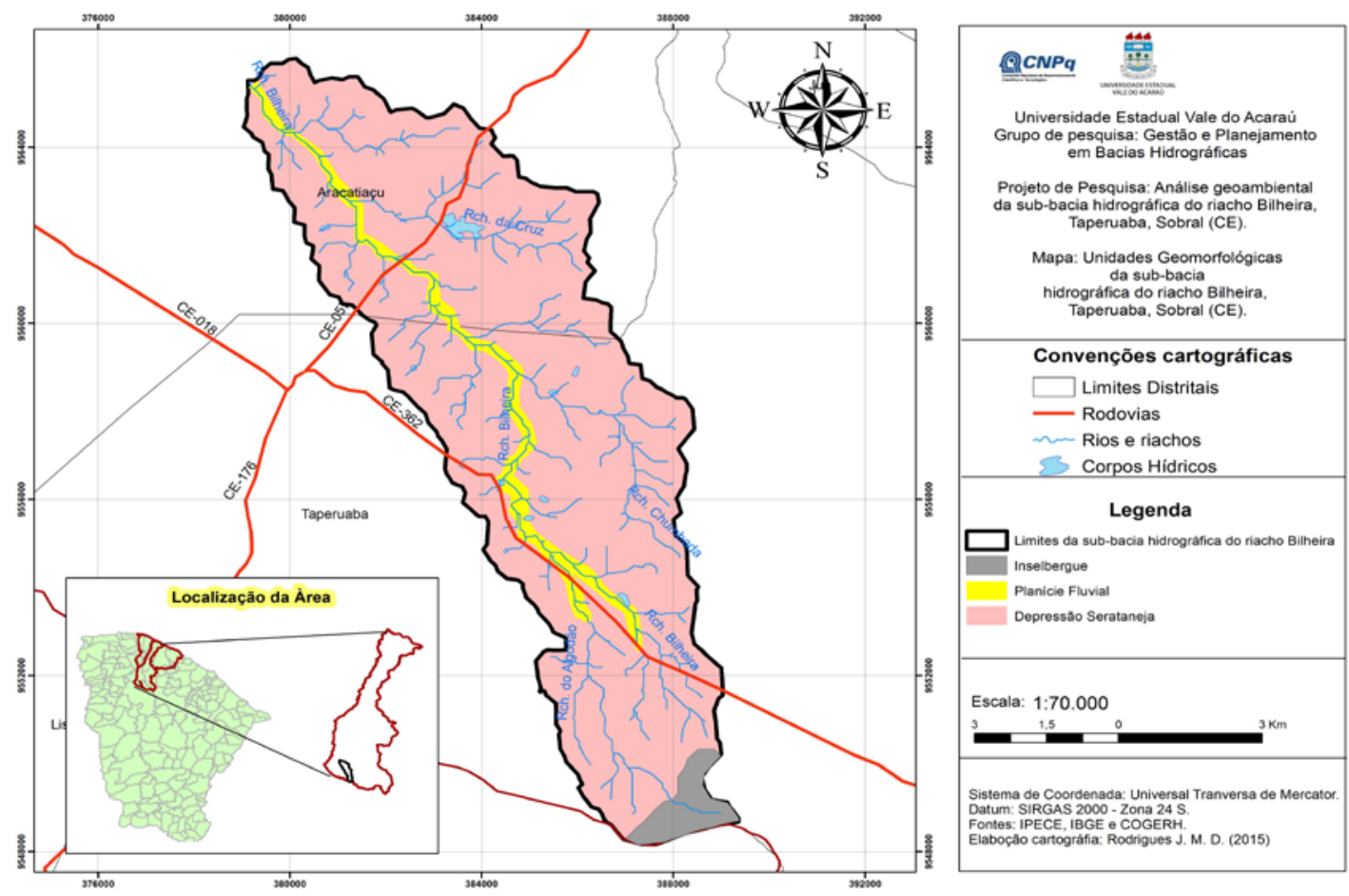

Figura 5. Compartimentação das unidades geomorfológicas da Sub-Bacia Hidrográfica do Riacho Bilheira. Fonte: Rodrigues (2016).

exatamente a esses atributos somados com a urbanização ao longo do Riacho Bilheira e de seus tributários.

Nesse contexto, analisou-se que toda a área de estudo possui um forte processo de degradação ambiental apresentando uma forte descaracterização da mata ciliar ao longo das margens do Riacho Bilheira e de suas nascentes, com presença de solos desnudos, ravinamentos, afloramentos rochosos e assoreamento dos cursos fluviais, porém temos que no alto curso ainda possuímos um ambiente parcialmente preservado.

A compartimentação geomorfológica apresentada procurou identificar e analisar as formas e as unidades de relevo encontradas na área, para a sub-bacia hidrográfica foram definidas três formas de relevo, sendo elas Inselbergues, caracterizadas nesse contexto como áreas ligeiramente elevadas com processos erosivos atuantes, Planície Fluvial entendidas como áreas de deposição de sedimentos encontrados ao longo do riacho Bilheira e de suas nascentes, Depressão
Sertaneja compreendendo a unidade geomorfológica mais expressiva na área e considerada como superfícies de aplainamento.

Dessa forma, pondera-se que a compartimentação geomorfológica poderá ser uma ferramenta importante para analisar a degradação ambiental, e um aporte metodológico riquíssimo para 0 planejamento ambiental, ressalta-se que a análise ambiental é imprescindível e essencial para se chegar a tais estudos.

\section{Declaração de conflito de interesses}

Os autores declaram não haver conflito de interesses.

\section{Referências}

Bertrand, G. Paisagem e Geografia Física Global: esboço metodológico. Caderno de Ciências da Terra, n. 13, p. 1-27, 1972.

Costa, L. B. Análise e proposta de zoneamento geoambiental da Sub-Bacia Hidrográfica do Riacho Santana, sudoeste do Rio Grande do Norte. Sobral: Universidade 
Estadual Vale do Acaraú, 2015. (Dissertação de mestrado).

Diniz, S. F.; Moreira, C. A.; Corradini, F. A. Susceptibilidade erosiva do baixo curso do Rio Acaraú-CE. Revista Geociências, v. 27, n. 3, p. 355-367, 2008.

EMBRAPA. Sistema Brasileiro de Classificação de Solos. 2 ed. Rio de Janeiro: EMBRAPA, 2006.

Fernandes, A. Temas fitogeográficos. Fortaleza: Stylus Comunicações, 1990.

FUNCEME. Compartimentação geoambiental do Estado do Ceará. Fortaleza: FUNCEME, 2009.

Lima, E. C. Planejamento ambiental como subsídio para gestão ambiental da bacia de drenagem do Açude Paulo Sarasate Varjota Ceará. Fortaleza: Universidade Federal do Ceará, 2012. (Tese de doutorado).

Lourenço, R. M. Diagnóstico físicoconservacionista como aporte para a análise da degradação no médio curso da Bacia Hidrográfica do Rio Aractiaçu (CE) - Brasil. Fortaleza: Universidade Federal do Ceará, 2013. (Dissertação de mestrado).
Rodrigues, J. M. D. Análise dos sistemas ambientais da Sub-bacia hidrográfica do rio Bom Jesus, Taperuaba, Ceará, Brasil. Sobral: Universidade Estadual Vale do Acaraú, 2016. (Dissertação de mestrado).

Penteado, M. M. Fundamentos de Geomorfologia. 3 ed. Rio de Janeiro: IBGE, 1983.

Souza, M. J. N; Lima, F. A. M; Paiva, J. B. Compartimentação topográfica do Estado do Ceará. Revista Ciência Agronomia, v 9, n.1/2, p. 78-85, 1979.

Trentin, R.; Santos, L. J. C; Robaina, L. E. S. Compartimentação geomorfológica da Bacia Hidrográfica do Rio Itu - Oeste do Rio Grande do Sul - Brasil. Revista Soc. \& Nat., n. 1, p. 127-142, 2012.

Tricart, J. Ecodinâmica. Rio de Janeiro: IBGE, 1977.

Troppmair, H.; Galina, M. H. Geossistemas. Revista Mercator, v. 5, n. 10, p. 80-88, 2006.

Troppmair, H. Geografia Física ou Geografia Ambiental? Modelos de Geografia Integrada. Bol. de Geografia Teorética, v. 15, n. 29/30, p. 63-69, 1985.

Informação da Licença: Este é um artigo Open Access distribuído sob os termos da Licença Creative Commons AtribuiçãoSemDerivações-SemDerivados, que permite o download do trabalho e o compartilhamento desde que seja atribuído o devido crédito, mas sem que possa ser alterado de nenhuma forma ou utilizá-los para fins comerciais. 